\title{
Some New Observations on Generalized Contractive Mappings and Related Results in $b$-Metric-Like Spaces
}

\author{
Tatjana Došenović (D), ${ }^{1}$ Manuel De La Sen $\left(\mathbb{D},{ }^{2}\right.$ Ljiljana Paunović $\left(\mathbb{D},{ }^{3}\right.$ Dušan Rakić (iD, ${ }^{1}$ \\ and Stojan Radenovićc $\mathbb{1}^{4}$ \\ ${ }^{1}$ Faculty of Technology Novi Sad, University of Novi Sad, Bulevar Cara Lazara 1, Novi Sad 21000, Serbia \\ ${ }^{2}$ Institute of Research and Development of Porocesses, University of the Basque Country, Leioa, Biscay, Spain \\ ${ }^{3}$ Teacher Education Faculty, University in Priština-Kosovska Mitrovica, Leposavić, Serbia \\ ${ }^{4}$ Faculty of Mechanical Engineering, University of Belgrade, Beograd, Serbia
}

Correspondence should be addressed to Manuel De La Sen; manuel.delasen@ehu.eus

Received 10 December 2020; Revised 11 February 2021; Accepted 2 March 2021; Published 20 March 2021

Academic Editor: Jen-Chih Yao

Copyright (C) 2021 Tatjana Došenović et al. This is an open access article distributed under the Creative Commons Attribution License, which permits unrestricted use, distribution, and reproduction in any medium, provided the original work is properly cited.

In this paper, we consider, discuss, complement, improve, generalize, and enrich some fixed point results obtained for $\left(\beta-\psi_{1}-\psi_{2}\right)$-contractive conditions in ordered $b$-metric-like spaces. By using our new approach for the proof that one Picard's sequence is $b_{b l}$-Cauchy in the context of $b$-metric-like spaces, we get much shorter proofs than the ones mentioned in the recent papers. Also, by the use of our method, we complement and enrich some common fixed point results for $\beta_{q, \phi}^{s, \psi}-$ contraction mappings. Our approach in this paper generalizes and modifies several comparable results in the existing literature.

\section{Introduction}

Fixed point theory is one of the most important areas of nonlinear analysis. At the beginning of the development, this part of analysis was related to the use of successive approximation in order to prove the existence and uniqueness of the solution of differential and integral equations. Later on, it is applied in various fields such as economics, physics, chemistry, differential and integral equations, partial differential equations, numerical analysis, and many others. Banach's contraction principle in metric spaces [1] is one of the most important results in fixed point theory and nonlinear analysis in general. In 1922, when Stefan Banach formulated the concept of contraction and proved the famous theorem, scientists around the world started publishing new results that are related either to the generalization of the contractive mapping such as Kannan, Chatterjea, Hardy-Rogers, Cirić, and many others or by generalizing space itself. By changing some axioms of ordinary metric space, new classes of so- called generalized metric spaces were obtained such as partial metric space, metric-like space, $b$-metric space, $b$-metric-like space, and others. For more details about fixed point theory in metric as well as generalized metric spaces, we encourage readers to see [2-9].

In each of them, Banach's well-known theorem is true in $b$-metric and $b$-metric-like spaces regardless of the magnitude of the coefficient $s$ in the triangle relation to each.

In [10], Matthews introduced the notion of a partial metric space where nonzero self-distance is considered, which has found great application in computer science. The second important generalization of metric spaces is so-called $b$-metric spaces. This concept was introduced by Bakhtin [11] and Czerwik [12] where the third axiom of metric spaces, referring to triangular inequality, weakened.

Furthermore, Amini Harandi [13] introduced the notion of metric-like space, as a generalization of a partial metric space, where all of the axioms of a metric is satisfied except that self-distance may be positive. 
In [14], the concept of $b$-metric-like space which generalizes the notions of partial metric space, metric-like space, and $b$-metric space is introduced.

Relations of the metric spaces and mentioned general$\begin{array}{lllll}\text { izations } & \text { are } & \text { illustrated as } & \text { follows }\left[\begin{array}{ll}15, & 16\end{array}\right]: \\ \text { metric space } & \longrightarrow & \text { partial metric space } & \longrightarrow & \text { metric-like space } \\ \downarrow & & \downarrow & \downarrow \\ \text { b-metric space } & \longrightarrow & \text { partial b-metric space } & \longrightarrow & \text { b-metric-like space }\end{array}$.

\section{Preliminaries}

Firstly, we present some definitions and basic notions of metric-like, $b$-metric-like spaces, $\alpha$-admissible mappings, $\left(\beta-\psi_{1}-\psi_{2}\right)$-contractive mappings of type-I and type-II, altering distance functions, $\beta_{q, \phi}^{s, \psi}$-contraction mappings, and ordered metric-like, that is, ordered $b$-metric-like space.

Definition 1 (see [13]). Let $X$ be a nonempty set. A mapping $b_{m l}: X \times X \longrightarrow[0,+\infty)$ is said to be metric-like if the following conditions hold for all $x, y, z \in X$ :
(i) $\left(b_{l} 1\right) b_{m l}(x, y)=0$ implies $x=y$
(ii) $\left(b_{l} 2\right) b_{m l}(x, y)=b_{m l}(y, x)$
(iii) $\left(b_{l} 3\right) b_{m l}(x, z) \leq b_{m l}(x, y)+b_{m l}(y, z)$

In this case, the pair $\left(X, b_{m l}\right)$ is called a metric-like space.

Definition 2 (see [14]). Let $X$ be a nonempty set and $s \geq 1$ be a given real number. $A b$-metric-like space on a nonempty set $X$ is a function $b_{b l}: X \times X \longrightarrow[0,+\infty)$ if the following conditions hold for all $x, y, z \in X$ :
(i) $\left(b_{b l} 1\right) b_{b l}(x, y)=0$ implying $x=y$
(ii) $\left(b_{b l} 2\right) b_{b l}(x, y)=b_{b l}(y, x)$
(iii) $\left(b_{b l} 3\right) b_{b l}(x, z) \leq s\left[b_{b l}(x, y)+b_{b l}(y, z)\right]$

In this case, the pair $\left(X, b_{b l}\right)$ is called a $b$-metric-like space with the coefficient constant $s \geq 1$.

For some examples, see [17-19] and [13, 20-25].

It is clear that each metric-like space is $b$-metric-like space, while the converse is not true. For more such examples and details see [9, 13, 14, 20, 24-27]. Also, for various metrics, but in the context of complex domain, see $[28,29]$.

Definition 3. A triple $\left(X, \precsim, b_{b l}\right)$ is said to be ordered $b$ metric-like space if $(X, \precsim)$ is a partially ordered set and $b_{b l}$ is a $b$-metric-like on $X$.

Now, we give the definition of convergence of the sequences in $b$-metric-like space.

Definition 4 (see [14]). Let $\left\{x_{n}\right\}$ be a sequence in a $b$-metriclike space $\left(X, b_{b l}\right)$ with the coefficient $s$.

(i) The sequence $\left\{x_{n}\right\}$ is said to be convergent to $x$ if $\lim _{n \longrightarrow \infty} b_{b l}\left(x_{n}, x\right)=b_{b l}(x, x)$

(ii) The sequence $\left\{x_{n}\right\}$ is said to be $b_{b l}$-Cauchy in $\left(X, b_{b l}\right)$ if $\lim _{n, m \rightarrow \infty} b_{b l}\left(x_{n}, x_{m}\right)$ exists and is finite (iii) One says that $b$-metric-like space $\left(X, b_{b l}\right)$ is a $b_{b l}$-complete if for every $b_{b l}$-Cauchy sequence $\left\{x_{n}\right\}$ in it there exists an $x \in X$, such that $\lim _{n, m \rightarrow \infty}$ $b_{b l}\left(x_{n}, x_{m}\right)=b_{b l}(x, x)=\lim _{n \longrightarrow \infty} b_{b l}\left(x_{n}, x\right)$

Properties such as convergence, completeness, and Cauchyness are introduced in the same way for metric and b-metric spaces. And, in these two types of spaces, the limits of the sequence if exists, is unique, as well as the convergent sequence is a Cauchy. Otherwise, for the other 4 types of space (partial metric, partial $b$-metric, metric-like, and $b$ metric like), this is not the case.

Remark 1. In a $b$-metric-like space, the limit of a sequence need not be unique and a convergent sequence need not be a $b_{b l}$-Cauchy sequence (see Example 7 in [20]). However, if the sequence $\left\{x_{n}\right\}$ is $b_{b l}$-Cauchy such that $\lim _{n, m \longrightarrow \infty} b_{b l}\left(x_{n}, x_{m}\right)=0$ in the $b_{b l}$-complete $b$-metric-like space $\left(X, b_{b l}\right)$ with coefficient $s \geq 1$, then the limit of such sequence is unique. Indeed, in such a case, if $x_{n} \longrightarrow x\left(b_{b l}\left(x_{n}, x\right) \longrightarrow b_{b l}(x, x)\right)$ as $n \longrightarrow \infty$, we get that $b_{b l}(x, x)=0$. Now, if $x_{n} \longrightarrow x$ and $x_{n} \longrightarrow y$, where $x \neq y$, we obtain that

$$
\begin{gathered}
\frac{1}{s} b_{b l}(x, y) \leq b_{b l}\left(x, x_{n}\right)+b_{b l}\left(x_{n}, y\right) \longrightarrow b_{b l}(x, x) \\
+b_{b l}(y, y)=0+0=0 .
\end{gathered}
$$

By $\left(b_{b l} 1\right)$, it follows that $x=y$. A contradiction.

Definition 5. Let $X$ be a nonempty set and suppose $f: X \longrightarrow X$ and $\beta: X \times X \longrightarrow[0,1)$ are mappings. $f$ is called $\beta$-admissible if for all $u, v \in X$,

$$
\beta(u, v) \geq 1 \text { implies } \beta(f(u), f(v)) \geq 1 .
$$

Also, we say that $f$ is $L_{\beta}$-admissible (or $R_{\beta}$-admissible) if for $u, v \in X$,

$$
\beta(u, v) \geq 1 \text { implies } \beta(f(u), v) \geq 1(\text { or } \beta(u, f(v)) \geq 1) .
$$

The next definition and the corresponding proposition are important in the context of fixed point theory.

Definition 6 (see [30]). A function $\psi:[0, \infty) \longrightarrow[0, \infty)$ is called an altering distance function if it satisfies the following properties:

(i) $\psi$ is continuous and nondecreasing

(ii) $\psi(t)=0$ iff $t=0$

Definition 7 (see [31]). The self-mappings $f, g: X \longrightarrow X$ are weakly compatible if $f(g(x))=g(f(x))$, whenever $f(x)=g(x)$.

Proposition 1 (see [31]). Let $f$ and $g$ be weakly compatible self-maps of a nonempty set $X$. If they have a unique point of coincidence $w=f(u)=g(u)$, then $w$ is the unique common fixed point of $f$ and $g$. 
In this paper, we shall use the following result for the proof that some Picard's sequence is $b_{b l}$-Cauchy. The proof is completely identical with the corresponding in [32] (see also [33-35]).

Lemma 1. Let $\left\{x_{n}\right\}$ be a sequence in a b-metric-like space $\left(X, b_{b l}\right)$ with the coefficient $s>1$ such that

$$
b_{b l}\left(x_{n}, x_{n+1}\right) \leq \lambda b_{b l}\left(x_{n-1}, x_{n}\right),
$$

for some $\lambda, 0 \leq \lambda<(1 / s)$, and each $n=1,2, \ldots$ Then, $\left\{x_{n}\right\}$ is a $b_{b l}$-Cauchy sequence in $\left(X, b_{b l}\right)$ such that $\lim _{n, m \rightarrow \infty}$ $b_{b l}\left(x_{n}, x_{m}\right)=0$.

Remark 2. It is worth to notice that the previous lemma holds in the context of $b$-metric-like spaces for each $\lambda \in[0,1)$. For more details, see [27].

Otherwise, many authors for the proof that some sequence in $b$-metric-like space is $b_{b l}$-Cauchy use the next lemma.

Lemma 2 (see [26]). Let $\left(X, b_{b l}\right)$ be a b-metric-like space with the coefficient $s>1$ and assume that $u_{n} \longrightarrow u$ and $v_{n} \longrightarrow v$ as $n \longrightarrow \infty$. Then, we have

$$
\begin{aligned}
\frac{1}{s^{2}} b_{b l}(u, u)-\frac{1}{s} b_{b l}(v, v) \leq & \liminf _{n \longrightarrow \infty} b_{b l}\left(u_{n}, v_{n}\right) \\
\leq & \operatorname{limsub}_{n \longrightarrow \infty} b_{b l}\left(u_{n}, v_{n}\right) \leq s b_{b l}(u, u) \\
& +s^{2} b_{b l}(v, v)+s^{2} b_{b l}(u, v) .
\end{aligned}
$$

In the case that the coefficient $s=1$, the given $b$-metric like space $\left(X, b_{b l}\right)$ becomes the metric-like space $\left(X, b_{m l}\right)$. If $\left\{x_{n}\right\}$ is a given sequence in the metric-like space $\left(X, b_{m l}\right)$, then we have the following very useful result.

Lemma 3 (see $[23,36])$. Let $\left(X, b_{m l}\right)$ be a metric-like space and let $\left\{x_{n}\right\}$ be a sequence in it such that $\lim _{n \longrightarrow \infty} b_{m l}\left(x_{n}, x_{n+1}\right)=0$. If $\left\{x_{n}\right\}$ is not a $b_{m l}$-Cauchy sequence in $\left(X, b_{m l}\right)$, then there exist $\varepsilon>0$ and two sequences $\left\{m_{k}\right\}$ and $\left\{n_{k}\right\}$ of positive integers such that $m_{k}>n_{k}>k$ and the following four sequences tend to $\varepsilon^{+}$when $k \longrightarrow \infty$ :

$$
b_{m l}\left(x_{m_{k}}, x_{n_{k}}\right), b_{m l}\left(x_{m_{k}}, x_{n_{k}+1}\right), b_{m l}\left(x_{m_{k}-1}, x_{n_{k}}\right), b_{m l}\left(x_{m_{k}-1}, x_{n_{k}+1}\right) \text {. }
$$

\section{Main Results}

In [37], the authors introduced two new types of contractive mappings, namely, $\left(\beta-\psi_{1}-\psi_{2}\right)$ contractive mappings of type-I and of type-II in ordered $b$-metric-like spaces.

Definition 8 (see [37], Definition 1 and Definition 4). Let $\left(X, \precsim, b_{b l}\right)$ be a partially ordered $b$-metric-like space with the coefficient $s \geq 1$. A mapping $f: X \longrightarrow X$ is said to be $\left(\beta-\psi_{1}-\psi_{2}\right)$-contractive mapping of type-I (resp., of type II), if there exist two altering distance functions $\psi_{1}, \psi_{2}$ and $\beta: X \times X \longrightarrow[0, \infty)$ such that

$$
\begin{aligned}
& \beta(u, f(u)) \beta(v, f(v)) \psi_{1}\left(s b_{b l}(f(u), f(v))\right) \\
& \leq \psi_{1}\left(\triangle_{s}^{f}(u, v)\right)-\psi_{2}\left(\triangle_{s}^{f}(u, v)\right),
\end{aligned}
$$

for all comparable $u, v \in X$, where

$$
\triangle_{s}^{f}(u, v)=\max \left\{\begin{array}{c}
b_{b l}(u, v), b_{b l}(u, f(u)), b_{b l}(v, f(v)), \frac{b_{b l}(u, f(v))+b_{b l}(v, f(u))}{4 s}, \\
\frac{b_{b l}(u, f(u)) b_{b l}(v, f(v))}{1+b_{b l}(u, v)}, \frac{b_{b l}(u, f(u)) b_{b l}(v, f(v))}{1+b_{b l}(f(u), f(v))}
\end{array}\right\}
$$

respectively,

$$
\triangle_{s}^{f}(u, v)=\max \left\{\begin{array}{c}
b_{b l}(u, v), b_{b l}(u, f(u)), b_{b l}(v, f(v)), \frac{b_{b l}(u, f(v))+b_{b l}(v, f(u))}{4 s}, \\
\frac{b_{b l}(u, f(u)) b_{b l}(u, f(v))+b_{b l}(v, f(v)) b_{b l}(v, f(u))}{1+s\left[b_{b l}(u, f(u))+b_{b l}(u, f(u))\right]}, \\
b_{b l}(u, f(u)) b_{b l}(u, f(v))+b_{b l}(v, f(v)) b_{b l}(v, f(u))
\end{array}\right\} .
$$


In [37], the authors proved the following results for $\left(\beta-\psi_{1}-\psi_{2}\right)$-contractive mapping of type-I (resp., of type II).

Theorem 1 (see [37], Theorem 2.2). Let $\left(X, \precsim, b_{b l}\right)$ be a $b_{b l}$-complete ordered $b$-metric-like space with the coefficient $s \geq 1$. Let $f: X \longrightarrow X$ be a $\left(\beta-\psi_{1}-\psi_{2}\right)$-contractive mapping of type-I. Assume that the following assertions hold:

(1) $f$ is $\beta$-admissible and $L_{\beta}$-admissible (or $R_{\beta}$-admissible)

(2) There exists $u_{1} \in X$ such that $u_{1} \precsim f\left(u_{1}\right)$ and $\beta\left(u_{1}, f\left(u_{1}\right)\right) \geq 1$

(3) $f$ is continuous, non-decreasing with respect to $\lesssim$, and if $f^{n}\left(u_{1}\right) \longrightarrow z$, then $\beta(z, z) \geq 1$

Then, $f$ has a fixed point.

Theorem 2 (see [37], Theorem 2.3). Let $\left(X, \precsim, b_{b l}\right)$ be a $b_{b l}$-complete ordered $b$-metric-like space with the coefficient $s \geq 1$. Let $f: X \longrightarrow X$ be a $\left(\beta-\psi_{1}-\psi_{2}\right)$-contractive mapping of type-I. Suppose that the following conditions hold:

(1) $f$ is $\beta$-admissible and $L_{\beta}$-admissible (or $R_{\beta}$-admissible)
(2) There exists $u_{1} \in X$ such that $u_{1} \precsim f\left(u_{1}\right)$ and $\beta\left(u_{1}, f\left(u_{1}\right)\right) \geq 1$

(3) $f$ is nondecreasing with respect to

(4) If $\left\{u_{n}\right\}$ is a sequence in $X$ such that $u_{n} \precsim u_{n+1}$ and $\beta\left(u_{n}, u_{n+1}\right) \geq 1$ for all $n \in \mathbb{N}$, and $u_{n} \longrightarrow u \in X$, as $n \longrightarrow \infty$, then $u_{n} \precsim u$ and $\beta\left(u_{n}, u\right) \geq 1$ for all $n \in \mathbb{N}$

Then, $f$ has a fixed point.

Theorem 3 (see [37], Theorem 2.5). Instead of the $\left(\beta-\psi_{1}-\psi_{2}\right)$-contractive mapping condition of type-I in Theorem 1, assume that $\left(\beta-\psi_{1}-\psi_{2}\right)$-contractive mapping condition of type-II is satisfied. Then, $f$ has a fixed point.

Similar to Theorem 2, the authors proved the following result.

Theorem 4. Let all the conditions of Theorem 2 are satisfied, apart from condition (8) which is replaced by (9). Then, $f$ has a fixed point.

Now, we give the shorter proofs of Theorems 1-4.

First, let $s>1$. Now, by applying (5) and (6) from [37], we get

$$
\begin{aligned}
\psi_{1}\left(s b_{b l}\left(u_{n+1}, u_{n+2}\right)\right) & \leq \beta\left(u_{n}, f\left(u_{n}\right)\right) \beta\left(u_{n+1}, f\left(u_{n+1}\right)\right) \psi_{1}\left(s b_{b l}\left(f\left(u_{n}\right), f\left(u_{n+1}\right)\right)\right) \\
& \leq \psi_{1}\left(\triangle_{s}^{f}\left(u_{n}, u_{n+1}\right)\right)-\psi_{2}\left(\triangle_{s}^{f}\left(u_{n}, u_{n+1}\right)\right)
\end{aligned}
$$

which is according to (7) from. $\triangle_{s}^{f}\left(u_{n}, u_{n+1}\right)$ $\leq \max \left\{b_{b l}\left(u_{n}, u_{n+1}\right), b_{b l}\left(u_{n+1}, u_{n+2}\right)\right\}$. It further follows that $s b_{b l}\left(u_{n+1}, u_{n+2}\right) \leq \max \left\{b_{b l}\left(u_{n}, u_{n+1}\right), b_{b l}\left(u_{n+1}, u_{n+2}\right)\right\}$. Since $s>1$, we get that $b_{b l}\left(u_{n+1}, u_{n+2}\right) \leq(1 / s) b_{b l}\left(u_{n}, u_{n+1}\right)$, that is, the sequence $\left\{u_{n}\right\}$ is a $b_{b l}$-Cauchy by to Remark 2 of Lemma 1. The proof is further the same as in [37].

If $s=1$, then the given contractive conditions in all Theorems in [37] imply that the corresponding Picard's sequence is $b_{m l}$-Cauchy according to Lemma 1 .

In [20], the authors introduced the so-called $\beta_{q, \phi}^{s, \psi}$-contraction mappings and obtained some common fixed point theorems for such contractions in the context of $b$-metric-like spaces.

First, let $\Psi, \Phi$ denote the class of functions $\psi, \phi:[0,+\infty) \longrightarrow[0,+\infty)$, respectively, satisfying the following conditions: (i) $\psi$ is nondecreasing, continuous function, and $\psi(t)=0$, if and only if $t=0$

(ii) $\phi$ is lower semicontinuous and $\phi(t)=0$, if and only if $t=0$

Definition 9 (see [20], Definition 5). Let $\left(X, b_{b l}\right)$ be a $b$-metric-like space with the coefficient $s \geq 1$. Let the constant $q \geq 2$ and $\beta \in[0,1)$. The nonlinear self-mappings $f, g: X \longrightarrow X$ are called $\beta_{q, \phi}^{s, \psi}$-contraction mappings if for all $x, y \in X$.

$$
\psi\left(2 s^{q} b_{b l}(f(x), f(y))\right) \leq \beta\left[\psi\left(M_{b l}(x, y)\right)-\phi\left(M_{b l}(x, y)\right)\right],
$$

where $\psi \in \Psi, \phi \in \Phi$, and

$$
M_{b l}(x, y)=\max \left\{b_{b l}(g(x), g(y)), b_{b l}(g(x), f(y)), b_{b l}(g(y), f(x)), \frac{b_{b l}(g(x), f(x))+b_{b l}(g(y), f(y))}{4 s}\right\} .
$$


Theorem 5 (see [20], Theorem 1). Let $\left(X, b_{b l}\right)$ be a $b_{b l}$-complete $b$-metric-like space with the coefficient $s \geq 1$, and $f, g: X \longrightarrow X$ be mapping satisfying the following conditions:

(i) $f(X) \subset g(X)$

(ii) The pair $(f, g)$ is a $\beta_{q, \phi}^{s, \psi}$-contraction

(iii) Then, $f$ and $g$ have a point of coincidence in $X$

(iv) Moreover, if $f$ and $g$ are weakly compatible, then $f$ and $g$ have a unique common fixed point in $X$
Remark 3. Some important remarks regarding the previous definition and theorem, namely, it is worth to notice that, for the set $M_{b l}(x, y)$ of real numbers from (11), we have

$$
\begin{aligned}
M_{b l}(x, y) \leq & \max \left\{b_{b l}(g(x), g(y)), b_{b l}(g(x), f(x)),\right. \\
& \left.b_{b l}(g(y), f(y))\right\} .
\end{aligned}
$$

Indeed, this follows from the known estimation: $\left(b_{b l}(g\right.$ $\left.(x), f(x))+b_{b l}(g(y), f(y)) / 4 s\right) \leq(1 / 2 s) \max \left\{b_{b l}(g(x)\right.$, $\left.f(x)), b_{b l}(g(y), f(y))\right\}$.

Therefore, instead of the set $M_{b l}(x, y)$ in [20], we introduce the next set:

$$
N_{b l}(x, y)=\max \left\{b_{b l}(g(x), g(y)), b_{b l}(g(x), f(x)), b_{b l}(g(y), f(y)), \frac{b_{b l}(g(x), f(y))+b_{b l}(g(y), f(x))}{4 s}\right\} .
$$

Now, we give the new formulation and the proof of Theorem 1 from [20] taking the set $N_{b l}(x, y)$ instead of $M_{b l}(x, y)$.

Theorem 6. Let $\left(X, b_{b l}\right)$ be a $b_{b l}$-complete $b$-metric-like space with the coefficient $s \geq 1$, and $f, g: X \longrightarrow X$ be a selfmapping satisfy the following conditions:

(i) $f(X) \subset g(X)$ and at least one of $f(X), g(X)$ is closed subset in the $\left(X, b_{b l}\right)$

(ii) the pair $(g, f)$ is an $\beta_{q, \phi}^{s, \psi}$ - contraction

(iii) Then $f$ and $g$ have a unique point of coincidence in $X$

(iv) Moreover, if $f$ and $g$ are weakly compatible, then $f$ and $g$ have a unique common fixed point in $X$
Proof

Step 1. Uniqueness of point of coincidence for pair $(f, g)$. First, suppose that the pair $(f, g)$ has at least one point of coincidence $\omega_{1}$. If it has other point of coincidence for example $\omega_{2} \neq \omega_{1}$, this means that there are two points $u_{1} \neq u_{2}$ from $X$ such that $\omega_{1}=f u_{1}=g u_{1}$ and $\omega_{2}=f u_{2}=g u_{2}$. According to (11) where $N_{b l}(x, y)$ is given with (14), we have

$$
\begin{aligned}
\psi\left(b_{b l}\left(f\left(u_{1}\right), f\left(u_{2}\right)\right)\right) & \leq \psi\left(2 s^{q} b_{b l}\left(f\left(u_{1}\right), f\left(u_{2}\right)\right)\right) \\
& \leq \beta\left[\psi\left(N_{b l}\left(u_{1}, u_{2}\right)\right)-\phi\left(N_{b l}\left(u_{1}, u_{2}\right)\right)\right],
\end{aligned}
$$

where

$$
\begin{aligned}
N_{b l}\left(u_{1}, u_{2}\right) & =\max \left\{b_{b l}\left(g\left(u_{1}\right), g\left(u_{2}\right)\right), b_{b l}\left(g\left(u_{1}\right), f\left(u_{1}\right)\right), b_{b l}\left(g\left(u_{2}\right), f\left(u_{2}\right)\right), \frac{b_{b l}\left(g\left(u_{1}\right), f\left(u_{2}\right)\right)+b_{b l}\left(g\left(u_{2}\right), f\left(u_{1}\right)\right)}{4 s}\right\} \\
& =\max \left\{b_{b l}\left(\omega_{1}, \omega_{2}\right), 0,0, \frac{b_{b l}\left(\omega_{1}, \omega_{2}\right)+b_{b l}\left(\omega_{1}, \omega_{2}\right)}{4 s}\right\}=b_{b l}\left(\omega_{1}, \omega_{2}\right) .
\end{aligned}
$$

Now, (15) becomes

$$
\begin{aligned}
\psi\left(b_{b l}\left(\omega_{1}, \omega_{2}\right)\right) & \leq \psi\left(2 s^{q} b_{b l}\left(\omega_{1}, \omega_{2}\right)\right) \\
& \leq \beta\left[\psi\left(b_{b l}\left(\omega_{1}, \omega_{2}\right)\right)-\phi\left(b_{b l}\left(\omega_{1}, \omega_{2}\right)\right)\right] \\
& <\psi\left(b_{b l}\left(\omega_{1}, \omega_{2}\right)\right)-\phi\left(b_{b l}\left(\omega_{1}, \omega_{2}\right)\right),
\end{aligned}
$$

that is, $\phi\left(b_{b l}\left(\omega_{1}, \omega_{2}\right)\right)=0$ which is a contradiction because $\omega_{1} \neq \omega_{2}$.

Step 2. Existence of the point of coincidence.

Let $x_{0}$ be an arbitrary point in $X$. Since $f(X) \subset g(X)$, there exists $x_{1} \in X$ such that $f x_{0}=g x_{1}$. By continuing this process inductively, we get two sequences $\left\{x_{n}\right\}$ and $\left\{z_{n}\right\}$ in $X$ such that

$$
z_{n}=f\left(x_{n}\right)=g\left(x_{n+1}\right) .
$$

If $b_{b l}\left(z_{k}, z_{k+1}\right)=0$ for some $k \in \mathbb{N}$, then $f\left(x_{k+1}\right)=g\left(x_{k+1}\right)$ is a unique point of coincidence for the pair $(f, g)$. Furthermore, let $b_{b l}\left(z_{n}, z_{n+1}\right)>0$, for all $n \in \mathbb{N}$. Now, we shall prove that

$$
b_{b l}\left(z_{n}, z_{n+1}\right) \leq \lambda b_{b l}\left(z_{n-1}, z_{n}\right)
$$

for some $\lambda \in(0,(1 / s))$. Indeed, according to (11) where instead of $M_{b l}$, we take $N_{b l}$, if $x=x_{n}, y=x_{n+1}$, we have 


$$
b_{b l}\left(z_{n}, z_{n+1}\right) \leq 2 s^{q} b_{b l}\left(z_{n}, z_{n+1}\right) \leq N_{b l}\left(x_{n}, x_{n+1}\right), \quad \text { (20) } \quad \text { where }
$$

$$
\begin{aligned}
N_{b l}\left(x_{n}, x_{n+1}\right) & =\max \left\{b_{b l}\left(g\left(x_{n}\right), g\left(x_{n+1}\right)\right), b_{b l}\left(g\left(x_{n}\right), f\left(x_{n}\right)\right), b_{b l}\left(g\left(x_{n+1}\right), f\left(x_{n+1}\right)\right), \frac{b_{b l}\left(g\left(x_{n}\right), f\left(x_{n+1}\right)\right)+b_{b l}\left(g\left(x_{n+1}\right), f\left(x_{n}\right)\right)}{4 s}\right\} \\
& =\max \left\{b_{b l}\left(z_{n-1}, z_{n}\right), b_{b l}\left(z_{n-1}, z_{n}\right), b_{b l}\left(z_{n}, z_{n+1}\right), \frac{b_{b l}\left(z_{n-1}, z_{n+1}\right)+0}{4 s}\right\} \\
& =\max \left\{b_{b l}\left(z_{n-1}, z_{n}\right), b_{b l}\left(z_{n}, z_{n+1}\right), \frac{b_{b l}\left(z_{n-1}, z_{n+1}\right)}{4 s}\right\} \leq \max \left\{b_{b l}\left(z_{n-1}, z_{n}\right), b_{b l}\left(z_{n}, z_{n+1}\right), \frac{b_{b l}\left(z_{n-1}, z_{n}\right)+b_{b l}\left(z_{n}, z_{n+1}\right)}{4}\right\} \\
& \leq \max \left\{b_{b l}\left(z_{n-1}, z_{n}\right), b_{b l}\left(z_{n}, z_{n+1}\right), \frac{b_{b l}\left(z_{n-1}, z_{n}\right)+b_{b l}\left(z_{n}, z_{n+1}\right)}{2}\right\} \leq \max \left\{b_{b l}\left(z_{n-1}, z_{n}\right), b_{b l}\left(z_{n}, z_{n+1}\right)\right\} .
\end{aligned}
$$

From (20) and (21), we get

$$
b_{b l}\left(z_{n}, z_{n+1}\right) \leq \frac{1}{2 s^{q}} \max \left\{b_{b l}\left(z_{n-1}, z_{n}\right), b_{b l}\left(z_{n}, z_{n+1}\right)\right\} \text {. }
$$

It is clear that $\max \left\{b_{b l}\left(z_{n-1}, z_{n}\right), b_{b l}\left(z_{n}, z_{n+1}\right)\right\}=b_{b l}$ $\left(z_{n-1}, z_{n}\right)$. Putting $\left(1 / 2 s^{q}\right)=\lambda \in(0,(1 / s))$, we obtain (19). Then, by Lemma 1 , the sequence $\left\{z_{n}\right\}$ is a $b_{b l}$-Cauchy sequence in the $b_{b l}$-complete $b$-metric-like space $\left(X, b_{b l}\right)$ such that $\lim _{n, m \rightarrow \infty} b_{b l}\left(z_{n}, z_{m}\right)$.

Let, for example, the subset $f(X)$ be closed. The proof if $g(X)$ is closed is similar. Then, in the first case, there is a unique point $u \in f(X)$ such that $z_{n}$ converges to $u$. Since $f(X) \subset g(X)$, there exists $v \in X$ such that $g(v)=u$. We shall show that $f(v)=g(v)=u$. For this proof, we firstly have

$$
\begin{aligned}
\frac{1}{s} b_{b l}(u, f(v)) & \leq b_{b l}\left(u, z_{n}\right)+b_{b l}\left(f\left(x_{n}\right), f(v)\right) \leq b_{b l}\left(u, z_{n}\right)+\frac{1}{2 s^{q}} N_{b l}\left(x_{n}, v\right) \\
N_{b l}\left(x_{n}, v\right) & =\max \left\{b_{b l}\left(g\left(x_{n}\right), g(v)\right), b_{b l}\left(g\left(x_{n}\right), f\left(x_{n}\right)\right), b_{b l}(g(v), f(v)), \frac{b_{b l}\left(g(v), f\left(x_{n}\right)\right)+b_{b l}\left(g\left(x_{n}\right), f(v)\right)}{4 s}\right\} \\
& =\max \left\{b_{b l}\left(z_{n-1}, u\right), b_{b l}\left(z_{n-1}, z_{n}\right), b_{b l}(u, f(v)), \frac{b_{b l}\left(u, z_{n}\right)+b_{b l}\left(z_{n-1}, f(v)\right)}{4 s}\right\} \\
& \leq \max \left\{b_{b l}\left(z_{n-1}, u\right), b_{b l}\left(z_{n-1}, z_{n}\right), b_{b l}(u, f(v)), \frac{b_{b l}\left(u, z_{n}\right)+s b_{b l}\left(z_{n-1}, u\right)+s b_{b l}(u, f(v))}{4 s}\right\} \\
& \longrightarrow b_{b l}(u, f(v)) \text { as } n \longrightarrow \infty .
\end{aligned}
$$

Letting the limit in (23) as $n \longrightarrow \infty$, we obtain $\frac{1}{s} b_{b l}(u, f(v)) \leq 0+\frac{1}{2 s^{q}} \cdot b_{b l}(u, f(v))=\frac{1}{2 s^{q}} \cdot b_{b l}(u, f(v))$.

(25) is possible only if $f(v)=u$. Hence, $u=f(v)=g(v)$ is a unique point of coincidence. The result further follows by Proposition 1 from [31]. This completes the proof of Theorem 6.

As corollaries of our Theorem 6, we obtain the next results:

Corollary 1. Let $\left(X, b_{b l}\right)$ be a $b_{b l}$-complete $b$-metric-like space with the coefficient $s \geq 1$, and $f, g: X \longrightarrow X$ be a weakly compatible mappings satisfying the following conditions:

(i) $f(X) \subset g(X)$ and at least one of $f(X), g(X)$ is a closed subset in the space $\left(X, b_{b}\right)$

(ii) Assume that $\psi \in \Psi, \phi \in \Phi, \beta \in[0,1)$ and $q \geq 2$ such that the condition

$$
\psi\left(2 s^{q} b_{b l}(f(x), f(y))\right) \leq \beta\left(\frac{\psi\left(N_{b l}(x, y)\right)}{1+\phi\left(N_{b l}(x, y)\right)}\right)
$$

holds for all $x, y \in X$

Then, $f$ and $g$ have a unique common fixed point in $X$. 
Proof

By (26), it follows that

$$
b_{b l}(f(x), f(y)) \leq \frac{1}{2 s^{q}} N_{b l}(x, y),
$$

for all $x, y \in X$. The result further follows from Theorem 6 .

Corollary 2. Let $\left(X, b_{b l}\right)$ be a $b_{b l}$-complete $b$-metric-like space with the coefficient $s \geq 1$, and $f, g: X \longrightarrow X$ be $a$ weakly compatible mappings satisfying the following conditions:

(i) $f(X) \subset g(X)$ and at least one of $f(X), g(X)$ is a closed subset in $\left(X, b_{b}\right)$

(ii) Assume that $\psi \in \Psi, \phi \in \Phi, \beta \in[0,1)$ and $q \geq 2$ such that the condition

$$
\psi\left(2 s^{q} b_{b l}(f(x), f(y))\right) \leq \beta\left(\frac{\psi\left(N_{b l}(x, y)\right) \phi\left(N_{b l}(x, y)\right)}{1+\phi\left(N_{b l}(x, y)\right)}\right),
$$

holds for all $x, y \in X$

Then, $f$ and $g$ have a unique common fixed point in $X$.

Proof

Condition (28) implies that

$$
\psi\left(2 s^{q} b_{b l}(f(x), f(y))\right) \leq \beta \psi\left(N_{b l}(x, y)\right),
$$

that is,

$$
b_{b l}(f(x), f(y)) \leq \frac{1}{2 s^{q}} N_{b l}(x, y)
$$

for all $x, y \in X$. Hence, the result follows by the previous corollary.

Corollary 3. Let $\left(X, b_{b l}\right)$ be a $b_{b l}$-complete $b$-metric-like space with the coefficient $s \geq 1$, and $f, g: X \longrightarrow X$ be a weakly compatible mappings satisfying the following conditions:

(i) $f(X) \subset g(X)$ and at least one of $f(X), g(X)$ is a closed subset in $\left(X, b_{b}\right)$

(ii) Assume that $\psi \in \Psi, \phi \in \Phi, \beta \in[0,1)$ and $q \geq 2$ such that the condition

$$
\psi\left(2 s^{q} b_{b l}(f(x), f(y))\right) \leq \beta\left(\frac{\psi\left(N_{b l}(x, y)\right)-\phi\left(N_{b l}(x, y)\right)}{1+\phi\left(N_{b l}(x, y)\right)}\right)
$$

holds for all $x, y \in X$

Then, $f$ and $g$ have a unique common fixed point in $X$.

Proof. It is clear that condition (31) implies (30). The proof then follows from Corollary 2.
In particular, by taking $\psi(t)=t$ and $f=g$ in Theorem 6, we have the following immediate result.

Corollary 4. Let $\left(X, b_{b l}\right)$ be a $b_{b l}$-complete $b$-metric-like space with the coefficient $s \geq 1$, and $f: X \longrightarrow X$ be a given self-mapping that satisfies

$$
s^{q} b_{b l}(f(x), f(y)) \leq \beta\left(N_{b l}(x, y)-\phi\left(N_{b l}(x, y)\right)\right),
$$

for all $x, y \in X$, where $f(X)$ is a closed subset in $\left(X, b_{b}\right)$.

Then, $f$ has a unique fixed point.

Putting $\psi(t)=t$ and $\phi(t)=(1 / 2) t$ in Theorem 6, we can get the next result.

Corollary 5. Let $\left(X, b_{b l}\right)$ be a $b_{b l}$-complete $b$-metric-like space with the coefficient $s \geq 1$, and $f, g: X \longrightarrow X$ be $a$ weakly compatible mappings satisfying the following conditions:

(i) $f(X) \subset g(X)$ and at least one of $f(X), g(X)$ is a closed subset in the space $\left(X, b_{b}\right)$

(ii) Assume that $\beta \in[0,1)$ and $q \geq 2$ such that the condition

$$
s^{q} b_{b l}(x, y) \leq \beta N_{b l}(x, y),
$$

holds for all $x, y \in X$

Then, $f$ and $g$ have a unique common fixed point in $X$.

Proof. It is an immediate consequence of Theorem 6.

Remark 4. By the known relation $a+b \leq 2 \max \{a, b\}$ for all real numbers $a, b$, authors in [20] obtained the next result as an immediate consequence of theirs (Theorem 1).

Corollary 6. Let $\left(X, b_{b l}\right)$ be a $b_{b l}$-complete $b$-metric-like space with the coefficient $s \geq 1$. If $f, g: \longrightarrow X \longrightarrow X$ be selfmappings, there exist $q \geq 2$ and real constants $c_{i} \geq 0, i=1, \ldots, 5$ with $\sum_{i=1}^{5} c_{i}<1$ such that

$$
\begin{aligned}
s^{q} b_{b l}(f(x), f(y)) \leq & c_{1} b_{b l}(g(x), g(y))+c_{2} b_{b l}(g(x), f(y)) \\
& +c_{3} b_{b l}(g(y), f(x))+c_{4} b_{b l}(g(x), f(x)) \\
& +c_{5} b_{b l}(g(y), f(y)),
\end{aligned}
$$

for all $x, y \in X$.

Then, $f$ and $g$ have a unique common fixed point, provided that the pair $(f, g)$ is a weakly compatible.

Remark 5. Lemmas 1 (for $s>1$ ) and 3 (for $s=1$ ) give the answer to a common question: does the given contractive condition imply that Picards's sequence initiated by any point $x_{0}$ is $b_{b l}$-Cauchy? 
Now, we have the following interesting question: does the weakly compatible self-mappings $f, g: X \longrightarrow X$ which satisfy condition (34) have a unique common fixed point in $X$ ?

\section{Data Availability}

No data were used to support this study.

\section{Conflicts of Interest}

The authors declare that they have no conflicts of interest.

\section{Acknowledgments}

The first, third, and fourth authors are supported by the Ministry of Education, Science and Technological Development of the Republic of Serbia (nos. 451-03-68/2020-14/ 200134 and 174002). The second author thanks the Basque Government for its support of this work through Grant IT1207-19.

\section{References}

[1] S. Banach, "Sur les opérations dans les ensembles abstraits et leur application aux équations intégrales," Fundamenta Mathematicae, vol. 3, pp. 133-181, 1922.

[2] R. P. Agarwal, E. Karapinar, D. O’Regan, and A. F. R. L. De Hierro, Fixed Point Theory in Metric Type Spaces, Springer International Publishing, New York, NY, USA, 2015.

[3] Lj. Cirić, Some Recent Results in Metrical Fixed Point Theory, University of Belgrade, Belgrade, Serbia, 2003.

[4] W. A. Kirk and N. Shahzad, Fixed Point Theory in Distance Spaces, Springer International Publishing Switzerland, New York, NY, USA, 2014.

[5] L. V. Nguyen and N. T. N. Tram, "Fixed point results with applications to involution mappings," Journal of Nonlinear and Convex Analysis, vol. 4, pp. 415-426, 2020.

[6] A. Petruşel and G. Petruşel, "Fixed point results for multivalued locally contractive operators," Applied Set-Valued Analysis and Optimization, vol. 2, pp. 175-181, 2020.

[7] B. E. Rhoades, "A comparison of various definitions of contractive mappings," Transactions of the American Mathematical Society, vol. 226, p. 257, 1977.

[8] B. Samet, C. Vetro, and P. Vetro, "Fixed point theorems for -contractive type mappings," Nonlinear Analysis: Theory, Methods \& Applications, vol. 75, no. 4, pp. 2154-2165, 2012.

[9] X.-Y. Zhao, F. He, and Y.-Q. Sun, "Common fixed point results for quasi-contractions of Ciric type in b-metric spaces with Qt-functions," Journal of Nonlinear Functional Analysis, vol. 2017, no. 1, pp. 1-18, 2017.

[10] S. G. Matthews, "Partial metric topology," Annals of the New York Academy of Sciences, vol. 728, no. 1, pp. 183-197, 1994.

[11] I. A. Bakhtin, "The contraction mapping principle in quasimetric spaces," Functional Analysis, vol. 30, pp. 26-37, 1989.

[12] S. Czerwik, "Contraction mappings in b-metric spaces," Acta Mathematica et Informatica Universitatis Ostraviensis, vol. 1, pp. 5-11, 1993.

[13] A. Amini-Harandi, "Metric-like spaces, partial metric spaces and fixed points," Fixed Point Theory and Algorithms, vol. 2012, Article ID 204, 2012.
[14] M. A. Alghmandi, N. Hussain, and P. Salimi, "Fixed point and coupled fixed point theorems on b-metric-like spaces," Journal of Inequalities and Applications, vol. 402, pp. 1-25, 2013.

[15] M. De la Sen, N. Nikolić, T. Došenović, M. Pavlović, and S. Radenović, "Some results on ( $s-\mathrm{q})$-graphic contraction mappings in b-metric-like spaces," Mathematics, vol. 7, no. 12, p. 1190, 2019.

[16] N. Fabiano, T. Došenović, D. Rakić, and S. Radenović, "Some new results on $(s, q)$ dass-gupta-jaggi type contractive mappings in $b$-Metric-Like space," Filomat, vol. 34, no. 12, pp. 4015-4026, 2020.

[17] H. Aydi, " $\alpha$-Implicit contractive pair of mapping on quasi-bmetric spaces and an application to integral equations," Journal of Nonlinear and Convex Analysis, vol. 17, pp. 2417-2433, 2016.

[18] H. Aydi, A. Felhi, and S. Sahmim, "On common fixed points for $(\alpha, \psi)$-contractions and generalized cyclic contractions in b-metric-like spaces and consequences," Journal of Nonlinear Sciences and Applications, vol. 09, no. 05, pp. 2492-2510, 2016.

[19] H. Aydi, A. Felhi, and S. Sahmim, "Common fixed points via implicit contractions on b-metric-like spaces," The Journal of Nonlinear Sciences and Applications, vol. 10, no. 04, pp. 1524-1537, 2017.

[20] H. A. Hammad and M. De la Sen, "Generalized contractive mappings and related results in b-metric like spaces with an application," Symmetry, vol. 11, 2019.

[21] A. Mukheimer, " $\alpha-\psi-\varphi$-contractive mappings in ordered partial b-metric spaces," Journal of Nonlinear Sciences and Applications, vol. 07, no. 03, pp. 168-179, 2014.

[22] H. Nashine and Z. Kadelburg, "Existence of solutions of cantilever beam problem via $(\alpha-\beta$-FG)-contractions in b-metric-like spaces," Filomat, vol. 31, no. 11, pp. 3057-3074, 2017.

[23] S. Shukla, S. Radenović, and V. Ć. Rajić, "Some common fixed point theorems in 0- $\sigma$-Complete metric-like spaces," Vietnam Journal of Mathematics, vol. 41, no. 3, pp. 341-352, 2013.

[24] K. Zoto, S. Radenović, and A. H. Ansari, "On some fixed point results for (s, p, $\alpha$ )-contractive mappings in b-metric-like spaces and applications to integral equations," Open Mathematics, vol. 16, no. 1, pp. 235-249, 2018.

[25] K. Zoto, B. E. Rhoades, and S. Radenović, "Some generalizations for $(\alpha-\psi, \phi)$-contractions in b-metric-like spaces and an application," Fixed Point Theory and Algorithms, vol. $25,2017$.

[26] N. Hussain, J. R. Roshan, V. Parvaneh, and Z. Kadelburg, "Fixed points of contractive mappings in b-metric-like spaces," Scientific World Journal, vol. 2014, Article ID 471827, 2014.

[27] J. Vujaković, H. Aydi, S. Radenović, and A. Mukheimer, "Some remarks and new results in ordered partial b-metric spaces," Mathematics, vol. 7, no. 4, p. 334, 2019.

[28] V. Todorčević, Harmonic Quasiconformal Mappings and Hyperbolic Type Metrics, Springer Nature Switzerland AG, New York, NY, USA, 2019.

[29] V. Todorčević, "Subharmonic behavior and quasiconformal mappings," Analysis and Mathematical Physics, vol. 9, pp. 1211-1225, 2019.

[30] M. S. Khan, M. Swaleh, and S. Sessa, "Fixed point theorems by altering distances between the points," Bulletin of the Australian Mathematical Society, vol. 30, no. 1, p. 1, 1984.

[31] M. Abbas and G. Jungck, "Common fixed point results for noncommuting mappings without continuity in cone metric 
spaces," Journal of Mathematical Analysis and Applications, vol. 341, no. 1, pp. 416-420, 2008.

[32] M. Jovanović, Z. Kadelburg, and S. Radenović, "Common fixed point results in metric-type spaces," Fixed Point Theory and Applications, vol. 2010, p. 978121, 2010.

[33] S. Aleksić, Z. D. Mitrović, and S. Radenović, "Picard sequences in b-metric spaces," Fixed Point Theory, vol. 21, no. 1, pp. 35-46, 2020.

[34] S. L. Singh, S. Czerwik, K. Krol, and A. Singh, "Coincidences and fixed points of hybrid contractions," Journal Tamsui Oxford Journal of Information and Mathematical Sciences, vol. 24, pp. 401-416, 2008.

[35] R. Miculescu and A. Mihail, "New fixed point theorems for set-valued contractions in b-metric spaces," Journal of Fixed Point Theory and Applications, vol. 19, no. 3, pp. 2153-2163, 2017.

[36] V. Ć. Rajić, S. Radenović, and S. Chauhan, "Common fixed point of generalized weakly contractive maps in partial metric spaces," Acta Mathematica Scientia, vol. 34, no. 4, pp. 13451356, 2014.

[37] S. K. Padhan, R. Jagannadha, H. Nashine, and R. P. Agarwal, "Some fixed point results for $(\beta-\psi 1-\psi 2)$-contractive conditions in ordered b-metric-like spaces," Filomat, vol. 31, no. 14, pp. 4587-4612, 2017. 